\title{
Some common fixed point theorems for a family of non-self mappings in cone metric spaces
}

\author{
Xianjiu Huang ${ }^{1}$, Chuanxi Zhu ${ }^{1 *}$, Xi Wen $^{2}$ and Ljubica Lalović ${ }^{3}$
}

\section{"Correspondence:}

chuanxizhu@126.com

'Department of Mathematics,

Nanchang University, Nanchang,

Jiangxi 330031, P.R. China

Full list of author information is

available at the end of the article

\begin{abstract}
Some common fixed point theorems for a family of non-self mappings defined on a closed subset of a metrically convex cone metric space (over the cone which is not necessarily normal) are obtained which generalize earlier results due to Imdad et al. and Janković et al.
\end{abstract}

MSC: $47 \mathrm{H} 10 ; 54 \mathrm{H} 25$

Keywords: cone metric spaces; common fixed point; non-self mappings

\section{Introduction and preliminaries}

The existing literature of fixed point theory contains many results enunciating fixed point theorems for self-mappings in metric and Banach spaces. Recently, Huang and Zhang [1] have replaced the real numbers by ordering Banach space and defining cone metric space. They have proved some fixed point theorems of contractive mappings on cone metric spaces. The study of fixed point theorems in such spaces is followed by some other mathematicians; see [2-17]. However, fixed point theorems for non-self mappings are not frequently discussed and so they form a natural subject for further investigation. The study of fixed point theorems for non-self mappings in metrically convex metric spaces was initiated by Assad and Kirk [18]. Recently, Janković et al. [10] obtained a fixed point theorem for two non-self mappings in cone metric spaces. Motivated by Janković et al. [10], we prove some common fixed point theorems for a family of non-self mappings on cone metric spaces in which the cone need not be normal.

Consistent with Huang and Zhang [1], the following definitions and results will be needed in the sequel.

Let $E$ be a real Banach space. A subset $P$ of $E$ is called a cone if and only if:

(a) $P$ is closed, nonempty and $P \neq\{\theta\}$;

(b) $a, b \in R, a, b \geq 0, x, y \in P$ implies $a x+b y \in P$;

(c) $P \cap(-P)=\{\theta\}$.

Given a cone $P \subset E$, we define a partial ordering $\preceq$ with respect to $P$ by $x \preceq y$ if and only if $y-x \in P$. A cone $P$ is called normal if there is a number $K>0$ such that for all $x, y \in E$,

$$
\theta \preceq x \preceq y \quad \text { implies } \quad\|x\| \leq K\|y\| .
$$

o 2013 Huang et al: licensee Springer. This is an Open Access article distributed under the terms of the Creative Commons Attribution License (http://creativecommons.org/licenses/by/2.0), which permits unrestricted use, distribution, and reproduction in any medium, provided the original work is properly cited. 
The least positive number $K$ satisfying the above inequality is called the normal constant of $P$, while $x \ll y$ stands for $y-x \in \operatorname{int} P$ (interior of $P$ ).

Definition 1.1 [1] Let $X$ be a nonempty set. Suppose that the mapping $d: X \times X \rightarrow E$ satisfies:

(d1) $\theta \preceq d(x, y)$ for all $x, y \in X$ and $d(x, y)=\theta$ if and only if $x=y$;

(d2) $d(x, y)=d(y, x)$ for all $x, y \in X$;

(d3) $d(x, y) \preceq d(x, z)+d(z, y)$ for all $x, y, z \in X$.

Then $d$ is called a cone metric on $X$ and $(X, d)$ is called a cone metric space.

The concept of a cone metric space is more general than that of a metric space.

Definition 1.2 [1] Let $(X, d)$ be a cone metric space. We say that $\left\{x_{n}\right\}$ is:

(e) a Cauchy sequence if for every $c \in E$ with $\theta \ll c$, there is an $N$ such that for all $n, m>N, d\left(x_{n}, x_{m}\right) \ll c ;$

(f) a convergent sequence if for every $c \in E$ with $\theta \ll c$, there is an $N$ such that for all $n>N, d\left(x_{n}, x\right) \ll c$ for some fixed $x \in X$.

A cone metric space $X$ is said to be complete if for every Cauchy sequence in $X$, it is convergent in $X$. It is known that $\left\{x_{n}\right\}$ converges to $x \in X$ if and only if $d\left(x_{n}, x\right) \rightarrow \theta$ as $n \rightarrow \infty$. It is a Cauchy sequence if and only if $d\left(x_{n}, x_{m}\right) \rightarrow \theta(n, m \rightarrow \infty)$.

Remark 1.1 [19] Let $E$ be an ordered Banach (normed) space. Then $c$ is an interior point of $P$, if and only if $[-c, c]$ is a neighborhood of $\theta$.

Corollary 1.1 [9] (1) If $a \preceq b$ and $b \ll c$, then $a \ll c$.

Indeed, $c-a=(c-b)+(b-a) \succeq c-b$ implies $[-(c-a), c-a] \supseteq[-(c-b), c-b]$.

(2) If $a \ll b$ and $b \ll c$, then $a \ll c$.

Indeed, $c-a=(c-b)+(b-a) \succeq c-b$ implies $[-(c-a), c-a] \supseteq[-(c-b), c-b]$.

(3) If $\theta \preceq u \ll c$ for each $c \in \operatorname{int} P$, then $u=\theta$.

Remark 1.2 [11] If $c \in \operatorname{int} P, \theta \preceq a_{n}$ and $a_{n} \rightarrow \theta$, then there exists an $n_{0}$ such that for all $n>n_{0}$, we have $a_{n} \ll c$.

Remark 1.3 [11] If $E$ is a real Banach space with cone $P$ and if $a \preceq k a$, where $a \in P$ and $0<k<1$, then $a=\theta$.

We find it convenient to introduce the following definition.

Definition 1.3 [11] Let $(X, d)$ be a complete cone metric space, let $C$ be a nonempty closed subset of $X$, and let $f, g: C \rightarrow X$ be non-self mappings. Denote, for $x, y \in C$,

$$
M_{1}^{f, g}=\left\{d(g x, g y), d(f x, g x), d(f y, g y), \frac{d(f x, g y)+d(f y, g x)}{2}\right\} .
$$

Then $f$ is called a generalized $g_{M_{1}}$-contractive mapping of $C$ into $X$ if, for some $\lambda \in(0$, $\sqrt{2}-1)$, there exists $u(x, y) \in M_{1}^{f, g}$ such that for all $x, y \in C$,

$$
d(f x, f y) \preceq \lambda u(x, y) .
$$


Definition 1.4 [2] Let $f$ and $g$ be self-maps of a set $X$ (i.e., $f, g: X \rightarrow X$ ). If $w=f x=g x$ for some $x$ in $X$, then $x$ is called a coincidence point of $f$ and $g$, and $w$ is called a point of coincidence of $f$ and $g$. Self-maps $f$ and $g$ are said to be coincidentally commuting if they commute at their coincidence point; i.e., if $f x=g x$ for some $x \in X$, then $f g x=g f x$.

\section{Main results}

Recently, Janković et al. [10] proved some fixed point theorems for a pair of non-self mappings defined on a nonempty closed subset of complete metrically convex cone metric spaces with new contractive conditions.

Theorem $2.1[10]$ Let $(X, d)$ be a complete cone metric space, let $C$ be a nonempty closed subset of $X$ such that for each $x \in C$ and $y \notin C$ there exists a point $z \in \partial C$ (the boundary of C) such that

$$
d(x, z)+d(z, y)=d(x, y) .
$$

Suppose that $f, g: C \rightarrow X$ are such that $f$ is a generalized $g_{M_{1}}$-contractive mapping of $C$ into $X$, and

(i) $\partial C \subseteq g C, f C \cap C \subseteq g C$,

(ii) $g x \in \partial C \Rightarrow f x \in C$,

(iii) $g C$ is closed in $X$.

Then the pair $(f, g)$ has a coincidence point. Moreover, if $(f, g)$ are coincidentally commuting, then $f$ and $g$ have a unique common fixed point.

The purpose of this paper is to extend the above theorem for a family of non-self mappings in cone metric spaces. We begin with the following definition.

Definition 2.1 Let $(X, d)$ be a complete cone metric space, let $C$ be a nonempty closed subset of $X$, and let $\left\{F_{n}\right\}_{n=1}^{\infty}, S, T: C \rightarrow X$ be non-self mappings. Denote, for $x, y \in C$,

$$
M_{1}^{F_{n}, S, T}=\left\{d(T x, S y), d\left(T x, F_{i} x\right), d\left(S y, F_{j} y\right), \frac{d\left(T x, F_{j} y\right)+d\left(F_{i} x, S y\right)}{2}\right\},
$$

where $i=2 n-1, j=2 n$ for some $n \in N$. Then $\left(F_{i}, F_{j}\right)$ is called a pair of generalized $(T, S)_{M_{1}}$ contractive mappings of $C$ into $X$ if for some $\lambda \in(0,1)$ there exists $u(x, y) \in M_{1}^{F_{n}, S, T}$ such that for all $x, y \in C$ with $x \neq y$,

$$
d\left(F_{i} x, F_{j} y\right) \preceq \lambda u(x, y) .
$$

Notice that by setting $F_{i}=F_{j}=f, T=S=g$ and $\lambda \in(0, \sqrt{2}-1)$ in (2.1), one deduces a slightly generalized form of (1.1).

We state and prove our main result as follows.

Theorem 2.2 Let $(X, d)$ be a complete cone metric space, let $C$ be a nonempty closed subset of $X$ such that for each $x \in C$ and $y \notin C$ there exists a point $z \in \partial C$ such that

$$
d(x, z)+d(z, y)=d(x, y) .
$$


Suppose that $F_{n}, S, T: C \rightarrow X$ are such that $\left(F_{i}, F_{j}\right)$ is a pair of generalized $(T, S)_{M_{1}}$ contractive mappings of $C$ into $X$ for all $i=2 n-1, j=2 n(n \in N)$, and

(I) $\partial C \subseteq S C \cap T C, F_{i} C \cap C \subseteq S C, F_{j} C \cap C \subseteq T C$,

(II) $T x \in \partial C$ implies that $F_{i} x \in C, S x \in \partial C$ implies that $F_{j} x \in C$,

(III) $S C$ and $T C$ (or $F_{i} C$ and $F_{j} C$ ) are closed in $X$.

Then

(IV) $\left(F_{i}, T\right)$ has a point of coincidence,

(V) $\left(F_{j}, S\right)$ has a point of coincidence.

Moreover, if $\left(F_{i}, T\right)$ and $\left(F_{j}, S\right)$ are coincidentally commuting pairs, then $\left\{F_{n}\right\}_{n=1}^{\infty}, S$ and $T$ have a unique common fixed point.

Proof Let $x \in \partial C$ be arbitrary. Then (due to $\partial C \subseteq T C$ ) there exists a point $x_{0} \in C$ such that $x=T x_{0}$. Since $T x_{0} \in \partial C$, from (I) and (II), we have $F_{1} x_{0} \in F_{1} C \cap C \subseteq S C$. Thus, there exists $x_{1} \in C$ such that $y_{1}=S x_{1}=F_{1} x_{0} \in C$. Since $y_{1}=F_{1} x_{0}$, there exists a point $y_{2}=F_{2} x_{1}$ such that

$$
d\left(y_{1}, y_{2}\right)=d\left(F_{1} x_{0}, F_{2} x_{1}\right) .
$$

Suppose $y_{2} \in C$. Then $y_{2} \in F_{2} C \cap C \subseteq T C$, which implies that there exists a point $x_{2} \in C$ such that $y_{2}=T x_{2}$. Otherwise, if $y_{2} \notin C$, then there exists a point $p \in \partial C$ such that

$$
d\left(S x_{1}, p\right)+d\left(p, y_{2}\right)=d\left(S x_{1}, y_{2}\right)
$$

Since $p \in \partial C \subseteq T C$, there exists a point $x_{2} \in C$ with $p=T x_{2}$ so that

$$
d\left(S x_{1}, T x_{2}\right)+d\left(T x_{2}, y_{2}\right)=d\left(S x_{1}, y_{2}\right) .
$$

Let $y_{3}=F_{3} x_{2}$ be such that $d\left(y_{2}, y_{3}\right)=d\left(F_{2} x_{1}, F_{3} x_{2}\right)$. Thus, repeating the foregoing arguments, one obtains two sequences $\left\{x_{n}\right\}$ and $\left\{y_{n}\right\}$ such that

(a) $y_{2 n}=F_{2 n} x_{2 n-1}, y_{2 n+1}=F_{2 n+1} x_{2 n}$,

(b) $y_{2 n} \in C$ implies that $y_{2 n}=T x_{2 n}$ or $y_{2 n} \notin C$ implies that $T x_{2 n} \in \partial C$ and

$$
d\left(S x_{2 n-1}, T x_{2 n}\right)+d\left(T x_{2 n}, y_{2 n}\right)=d\left(S x_{2 n-1}, y_{2 n}\right)
$$

(c) $y_{2 n+1} \in C$ implies that $y_{2 n+1}=S x_{2 n+1}$ or $y_{2 n+1} \notin C$ implies that $S x_{2 n+1} \in \partial C$ and

$$
d\left(T x_{2 n}, S x_{2 n+1}\right)+d\left(S x_{2 n+1}, y_{2 n+1}\right)=d\left(T x_{2 n}, y_{2 n+1}\right) .
$$

We denote

$$
\begin{aligned}
& P_{0}=\left\{T x_{2 i} \in\left\{T x_{2 n}\right\}: T x_{2 i}=y_{2 i}\right\}, \\
& P_{1}=\left\{T x_{2 i} \in\left\{T x_{2 n}\right\}: T x_{2 i} \neq y_{2 i}\right\}, \\
& Q_{0}=\left\{S x_{2 i+1} \in\left\{S x_{2 n+1}\right\}: S x_{2 i+1}=y_{2 i+1}\right\}, \\
& Q_{1}=\left\{S x_{2 i+1} \in\left\{S x_{2 n+1}\right\}: S x_{2 i+1} \neq y_{2 i+1}\right\} .
\end{aligned}
$$


Note that $\left(T x_{2 n}, S x_{2 n+1}\right) \notin P_{1} \times Q_{1}$, as if $T x_{2 n} \in P_{1}$, then $y_{2 n} \neq T x_{2 n}$ and one infers that $T x_{2 n} \in \partial C$, which implies that $y_{2 n+1}=F_{2 n+1} x_{2 n} \in C$. Hence $y_{2 n+1}=S x_{2 n+1} \in Q_{0}$. Similarly, one can argue that $\left(S x_{2 n-1}, T x_{2 n}\right) \notin Q_{1} \times P_{1}$.

Now, we distinguish the following three cases.

Case 1. If $\left(T x_{2 n}, S x_{2 n+1}\right) \in P_{0} \times Q_{0}$, then from (2.2)

$$
d\left(T x_{2 n}, S x_{2 n+1}\right)=d\left(F_{2 n+1} x_{2 n}, F_{2 n} x_{2 n-1}\right) \preceq \lambda u_{2 n-1},
$$

where

$$
\begin{aligned}
u_{2 n-1} \in & \left\{d\left(S x_{2 n-1}, T x_{2 n}\right), d\left(S x_{2 n-1}, F_{2 n} x_{2 n-1}\right), d\left(T x_{2 n}, F_{2 n+1} x_{2 n}\right),\right. \\
& \left.\frac{d\left(T x_{2 n}, F_{2 n} x_{2 n-1}\right)+d\left(S x_{2 n-1}, F_{2 n+1} x_{2 n}\right)}{2}\right\} \\
= & \left\{d\left(y_{2 n-1}, y_{2 n}\right), d\left(y_{2 n}, y_{2 n+1}\right), \frac{d\left(y_{2 n-1}, y_{2 n+1}\right)}{2}\right\} .
\end{aligned}
$$

Clearly, there are infinitely many $n$ such that at least one of the following three cases holds:

(1) $d\left(T x_{2 n}, S x_{2 n+1}\right) \preceq \lambda d\left(y_{2 n-1}, y_{2 n}\right)=\lambda d\left(S x_{2 n-1}, T x_{2 n}\right)$;

(2) $d\left(T x_{2 n}, S x_{2 n+1}\right) \preceq \lambda d\left(y_{2 n}, y_{2 n+1}\right)$ implies that $d\left(T x_{2 n}, S x_{2 n+1}\right)=\theta \preceq \lambda d\left(S x_{2 n-1}, T x_{2 n}\right)$;

(3) $d\left(T x_{2 n}, S x_{2 n+1}\right) \preceq \lambda \frac{d\left(y_{2 n-1}, y_{2 n+1}\right)}{2} \preceq \frac{\lambda}{2} d\left(y_{2 n-1}, y_{2 n}\right)+\frac{1}{2} d\left(y_{2 n}, y_{2 n+1}\right)$ implies that $d\left(T x_{2 n}, S x_{2 n+1}\right) \preceq \lambda d\left(S x_{2 n-1}, T x_{2 n}\right)$.

From (1), (2), (3) it follows that

$$
d\left(T x_{2 n}, S x_{2 n+1}\right) \preceq \lambda d\left(S x_{2 n-1}, T x_{2 n}\right) .
$$

Similarly, if $\left(S x_{2 n+1}, T x_{2 n+2}\right) \in Q_{0} \times P_{0}$, we have

$$
d\left(S x_{2 n+1}, T x_{2 n+2}\right)=d\left(F_{2 n+1} x_{2 n}, F_{2 n+2} x_{2 n+1}\right) \preceq \lambda d\left(T x_{2 n}, S x_{2 n+1}\right) .
$$

If $\left(S x_{2 n-1}, T x_{2 n}\right) \in Q_{0} \times P_{0}$, we have

$$
d\left(S x_{2 n-1}, T x_{2 n}\right)=d\left(F_{2 n-1} x_{2 n-2}, F_{2 n} x_{2 n-1}\right) \preceq \lambda d\left(T x_{2 n-2}, S x_{2 n-1}\right) .
$$

Case 2. If $\left(T x_{2 n}, S x_{2 n+1}\right) \in P_{0} \times Q_{1}$, then $S x_{2 n+1} \in Q_{1}$ and

$$
d\left(T x_{2 n}, S x_{2 n+1}\right)+d\left(S x_{2 n+1}, y_{2 n+1}\right)=d\left(T x_{2 n}, y_{2 n+1}\right),
$$

which in turn yields

$$
d\left(T x_{2 n}, S x_{2 n+1}\right) \preceq d\left(T x_{2 n}, y_{2 n+1}\right)=d\left(y_{2 n}, y_{2 n+1}\right)
$$

and hence

$$
d\left(T x_{2 n}, S x_{2 n+1}\right) \preceq d\left(y_{2 n}, y_{2 n+1}\right)=d\left(F_{2 n+1} x_{2 n}, F_{2 n} x_{2 n-1}\right) .
$$


Now, proceeding as in Case 1, we have that (2.3) holds.

If $\left(S x_{2 n+1}, T x_{2 n+2}\right) \in Q_{1} \times P_{0}$, then $T x_{2 n} \in P_{0}$. We show that

$$
d\left(S x_{2 n+1}, T x_{2 n+2}\right) \preceq \lambda d\left(T x_{2 n}, S x_{2 n-1}\right) .
$$

Using (2.6), we get

$$
\begin{aligned}
d\left(S x_{2 n+1}, T x_{2 n+2}\right) & \preceq d\left(S x_{2 n+1}, y_{2 n+1}\right)+d\left(y_{2 n+1}, T x_{2 n+2}\right) \\
& =d\left(T x_{2 n}, y_{2 n+1}\right)-d\left(T x_{2 n}, S x_{2 n+1}\right)+d\left(y_{2 n+1}, T x_{2 n+2}\right) .
\end{aligned}
$$

By noting that $T x_{2 n+2}, T x_{2 n} \in P_{0}$, one can conclude that

$$
d\left(y_{2 n+1}, T x_{2 n+2}\right)=d\left(y_{2 n+1}, y_{2 n+2}\right)=d\left(F_{2 n+1} x_{2 n}, F_{2 n+2} x_{2 n+1}\right) \preceq \lambda d\left(T x_{2 n}, S x_{2 n+1}\right)
$$

and

$$
d\left(T x_{2 n}, y_{2 n+1}\right)=d\left(y_{2 n}, y_{2 n+1}\right)=d\left(F_{2 n+1} x_{2 n}, F_{2 n} x_{2 n-1}\right) \preceq \lambda d\left(S x_{2 n-1}, T x_{2 n}\right),
$$

in view of Case 1.

Thus,

$$
d\left(S x_{2 n+1}, T x_{2 n+2}\right) \preceq \lambda d\left(S x_{2 n-1}, T x_{2 n}\right)-(1-\lambda) d\left(T x_{2 n}, S x_{2 n+1}\right) \preceq \lambda d\left(S x_{2 n-1}, T x_{2 n}\right),
$$

and we proved (2.9).

Case 3. If $\left(T x_{2 n}, S x_{2 n+1}\right) \in P_{1} \times Q_{0}$, then $S x_{2 n-1} \in Q_{0}$. We show that

$$
d\left(T x_{2 n}, S x_{2 n+1}\right) \preceq \lambda d\left(S x_{2 n-1}, T x_{2 n-2}\right) .
$$

Since $T x_{2 n} \in P_{1}$, then

$$
d\left(S x_{2 n-1}, T x_{2 n}\right)+d\left(T x_{2 n}, y_{2 n}\right)=d\left(S x_{2 n-1}, y_{2 n}\right)
$$

From this, we get

$$
\begin{aligned}
d\left(T x_{2 n}, S x_{2 n+1}\right) & \preceq d\left(T x_{2 n}, y_{2 n}\right)+d\left(y_{2 n}, S x_{2 n+1}\right) \\
& =d\left(S x_{2 n-1}, y_{2 n}\right)-d\left(S x_{2 n-1}, T x_{2 n}\right)+d\left(y_{2 n}, S x_{2 n+1}\right) .
\end{aligned}
$$

By noting that $S x_{2 n+1}, S x_{2 n-1} \in Q_{0}$, one can conclude that

$$
d\left(y_{2 n}, S x_{2 n+1}\right)=d\left(y_{2 n}, y_{2 n+1}\right)=d\left(F_{2 n+1} x_{2 n}, F_{2 n} x_{2 n-1}\right) \preceq \lambda d\left(S x_{2 n-1}, T x_{2 n}\right)
$$

and

$$
d\left(S x_{2 n-1}, y_{2 n}\right)=d\left(y_{2 n-1}, y_{2 n}\right)=d\left(F_{2 n-1} x_{2 n-2}, F_{2 n} x_{2 n-1}\right) \preceq \lambda d\left(S x_{2 n-1}, T x_{2 n-2}\right),
$$

in view of Case 1. 
Thus,

$$
d\left(T x_{2 n}, S x_{2 n+1}\right) \preceq \lambda d\left(S x_{2 n-1}, T x_{2 n-2}\right)-(1-\lambda) d\left(S x_{2 n-1}, T x_{2 n}\right) \preceq \lambda d\left(S x_{2 n-1}, T x_{2 n-2}\right),
$$

and we proved (2.13).

Similarly, if $\left(S x_{2 n+1}, T x_{2 n+2}\right) \in Q_{0} \times P_{1}$, then $T x_{2 n+2} \in P_{1}$, and

$$
d\left(S x_{2 n+1}, T x_{2 n+2}\right)+d\left(T x_{2 n+2}, y_{2 n+2}\right)=d\left(S x_{2 n+1}, y_{2 n+2}\right) .
$$

From this, we have

$$
\begin{aligned}
d\left(S x_{2 n+1}, T x_{2 n+2}\right) & \leq d\left(S x_{2 n+1}, y_{2 n+2}\right)+d\left(y_{2 n+2}, T x_{2 n+2}\right) \\
& \leq d\left(S x_{2 n+1}, y_{2 n+2}\right)+d\left(S x_{2 n+1}, y_{2 n+2}\right)-d\left(S x_{2 n+1}, T x_{2 n+2}\right) \\
& =2 d\left(S x_{2 n+1}, y_{2 n+2}\right)-d\left(S x_{2 n+1}, T x_{2 n+2}\right) .
\end{aligned}
$$

This implies that $d\left(S x_{2 n+1}, T x_{2 n+2}\right) \preceq d\left(S x_{2 n+1}, y_{2 n+2}\right)$.

By noting that $S x_{2 n+1} \in Q_{0}$, one can conclude that

$$
\begin{aligned}
d\left(S x_{2 n+1}, T x_{2 n+2}\right) & \leq d\left(S x_{2 n+1}, y_{2 n+2}\right) \\
& =d\left(F_{2 n+1} x_{2 n}, F_{2 n+2} x_{2 n+1}\right) \preceq \lambda d\left(T x_{2 n}, S x_{2 n+1}\right),
\end{aligned}
$$

in view of Case 1.

Thus, in all Cases 1-3, there exists $w_{2 n} \in\left\{d\left(S x_{2 n-1}, T x_{2 n}\right), d\left(T x_{2 n-2}, S x_{2 n-1}\right)\right\}$ such that

$$
d\left(T x_{2 n}, S x_{2 n+1}\right) \preceq \lambda w_{2 n}
$$

and there exists $w_{2 n+1} \in\left\{d\left(S x_{2 n-1}, T x_{2 n}\right), d\left(T x_{2 n}, S x_{2 n+1}\right)\right\}$ such that

$$
d\left(S x_{2 n+1}, T x_{2 n+2}\right) \preceq \lambda w_{2 n+1} .
$$

Following the procedure of Assad and Kirk [18], it can easily be shown by induction that, for $n \geq 1$, there exists $w_{2} \in\left\{d\left(T x_{0}, S x_{1}\right), d\left(S x_{1}, T x_{2}\right)\right\}$ such that

$$
d\left(T x_{2 n}, S x_{2 n+1}\right) \preceq \lambda^{n-\frac{1}{2}} w_{2} \text { and } d\left(S x_{2 n+1}, T x_{2 n+2}\right) \preceq \lambda^{n} w_{2} .
$$

From (2.19) and by the triangle inequality, for $n>m$, we have

$$
\begin{aligned}
d\left(T x_{2 n}, S x_{2 m+1}\right) & \preceq d\left(T x_{2 n}, S x_{2 n-1}\right)+d\left(S x_{2 n-1}, T x_{2 n-2}\right)+\cdots+d\left(T x_{2 m+2}, S x_{2 m+1}\right) \\
& \preceq\left(\lambda^{m}+\lambda^{m+\frac{1}{2}}+\cdots+\lambda^{n-1}\right) w_{2} \preceq \frac{\lambda^{m}}{1-\sqrt{\lambda}} w_{2} \rightarrow \theta, \quad \text { as } m \rightarrow \infty .
\end{aligned}
$$

From Remark 1.2 and Corollary 1.1(1), $d\left(T x_{2 n}, S x_{2 m+1}\right) \ll c$.

Thus, the sequence $\left\{T x_{0}, S x_{1}, T x_{2}, S x_{3}, \ldots, S x_{2 n-1}, T x_{2 n}, S x_{2 n-1}, \ldots\right\}$ is a Cauchy sequence. Then, as noted in [20], there exists at least one subsequence $\left\{T x_{2 n_{k}}\right\}$ or $\left\{S x_{2 n_{k}+1}\right\}$ which is contained in $P_{0}$ or $Q_{0}$, respectively, having as a limit point $z$. Furthermore, subsequences 
$\left\{T x_{2 n_{k}}\right\}$ and $\left\{S x_{2 n_{k}+1}\right\}$ both converge to $z \in C$ as $C$ is a closed subset of a complete cone metric space $(X, d)$. We assume that there exists a subsequence $\left\{T x_{2 n_{k}}\right\} \subseteq P_{0}$ for each $k \in N$, and $T C$ as well as $S C$ are closed in $X$. Since $\left\{T x_{2 n_{k}}\right\}$ is a Cauchy sequence in $T C$, it converges to a point $z \in T C$. Let $w \in T^{-1} z$, then $T w=z$. Similarly, $\left\{S x_{2 n_{k}+1}\right\}$ being a subsequence of the Cauchy sequence $\left\{T x_{0}, S x_{1}, T x_{2}, S x_{3}, \ldots, S x_{2 n-1}, T x_{2 n}, S x_{2 n-1}, \ldots\right\}$ also converges to $z$ as $S C$ is closed. Using (2.2), one can write

$$
d\left(F_{i} w, z\right) \preceq d\left(F_{i} w, F_{j} x_{2 n_{k}-1}\right)+d\left(F_{j} x_{2 n_{k}-1}, z\right) \preceq \lambda u_{2 n_{k}-1}+d\left(F_{j} x_{2 n_{k}-1}, z\right),
$$

where

$$
\begin{aligned}
u_{2 n_{k}-1} \in & \left\{d\left(T w, S x_{2 n_{k}-1}\right), d\left(T w, F_{i} w\right), d\left(S x_{2 n_{k}-1}, F_{j} x_{2 n_{k}-1}\right),\right. \\
& \left.\frac{d\left(T w, F_{j} x_{2 n_{k}-1}\right)+d\left(F_{i} w, S x_{2 n_{k}-1}\right)}{2}\right\} \\
= & \left\{d\left(z, S x_{2 n_{k}-1}\right), d\left(z, F_{i} w\right), d\left(S x_{2 n_{k}-1}, F_{j} x_{2 n_{k}-1}\right), \frac{d\left(z, F_{j} x_{2 n_{k}-1}\right)+d\left(F_{i} w, S x_{2 n_{k}-1}\right)}{2}\right\}
\end{aligned}
$$

for any odd integer $i \in N$ and even integer $j \in N$.

Let $\theta \ll c$. Clearly at least one of the following four cases holds for infinitely many $n$.

(1) $d\left(F_{i} w, z\right) \preceq \lambda d\left(z, S x_{2 n_{k}-1}\right)+d\left(F_{j} x_{2 n_{k}-1}, z\right) \ll \lambda \frac{c}{2 \lambda}+\frac{c}{2}=c$;

(2) $d\left(F_{i} w, z\right) \preceq \lambda d\left(z, F_{i} w\right)+d\left(F_{j} x_{2 n_{k}-1}, z\right) \Rightarrow d\left(F_{i} w, z\right) \preceq \frac{1}{1-\lambda} d\left(F_{j} x_{2 n_{k}-1}, z\right) \ll$ $\frac{1}{1-\lambda}(1-\lambda) c=c$

(3)

$$
\begin{aligned}
d\left(F_{i} w, z\right) & \leq \lambda d\left(S x_{2 n_{k}-1}, F_{j} x_{2 n_{k}-1}\right)+d\left(F_{j} x_{2 n_{k}-1}, z\right) \\
& \leq \lambda\left(d\left(S x_{2 n_{k}-1}, z\right)+d\left(z, F_{j} x_{2 n_{k}-1}\right)\right)+d\left(F_{j} x_{2 n_{k}-1}, z\right) \\
& \leq(\lambda+1) d\left(F_{j} x_{2 n_{k}-1}, z\right)+\lambda d\left(S x_{2 n_{k}-1}, z\right) \ll(\lambda+1) \frac{c}{2(\lambda+1)}+\lambda \frac{c}{2 \lambda}=c ;
\end{aligned}
$$

$(4)$

$$
\begin{aligned}
& d\left(F_{i} w, z\right) \preceq \lambda \frac{d\left(z, F_{j} x_{2 n_{k}-1}\right)+d\left(F_{i} w, S x_{2 n_{k}-1}\right)}{2}+d\left(F_{j} x_{2 n_{k}-1}, z\right) \\
& \preceq \lambda \frac{d\left(z, F_{j} x_{2 n_{k}-1}\right)+d\left(z, S x_{2 n_{k}-1}\right)}{2}+\frac{1}{2} d\left(F_{i} w, z\right)+d\left(F_{j} x_{2 n_{k}-1}, z\right) \\
& \Rightarrow \quad d\left(F_{i} w, z\right) \preceq(2+\lambda) d\left(F_{j} x_{2 n_{k}-1}, z\right)+\lambda d\left(z, S x_{2 n_{k}-1}\right) \\
& \ll(2+\lambda) \frac{c}{2(2+\lambda)}+\lambda \frac{c}{2 \lambda}=c .
\end{aligned}
$$

In all cases, we obtain $d\left(F_{i} w, z\right) \ll c$ for each $c \in \operatorname{int} P$. Using Corollary 1.1(3), it follows that $d\left(F_{i} w, z\right)=\theta$ or $F_{i} w=z$. Thus, $F_{i} w=z=T w$, that is, $z$ is a coincidence point of $F_{i}, T$ for any odd integer $i \in N$.

Further, since the Cauchy sequence $\left\{T_{x_{2 n_{k}}}\right\}$ converges to $z \in C$ and $z=F_{i} w, z \in F_{i} C \cap C \subseteq$ $S C$, there exists $v \in C$ such that $S v=z$. Again, using (2.2), we get

$$
d\left(S v, F_{j} v\right)=d\left(z, F_{j} v\right)=d\left(F_{i} w, F_{j} v\right) \preceq \lambda u,
$$


where

$$
\begin{aligned}
u & \in\left\{d(T w, S v), d\left(T w, F_{i} w\right), d\left(S v, F_{j} v\right), \frac{d\left(T w, F_{j} v\right)+d\left(F_{i} w, S v\right)}{2}\right\} \\
& =\left\{\theta, \theta, d\left(S v, F_{j} v\right), \frac{d\left(z, F_{j} v\right)+\theta}{2}\right\}=\left\{\theta, d\left(S v, F_{j} v\right), \frac{d\left(S v, F_{j} v\right)}{2}\right\}
\end{aligned}
$$

for any odd integer $i \in N$ and even integer $j \in N$.

Hence, we get the following cases:

$$
\begin{aligned}
& d\left(S v, F_{j} v\right) \preceq \lambda \theta=\theta, \quad d\left(S v, F_{j} v\right) \preceq \lambda d\left(S v, F_{j} v\right) \quad \text { and } \\
& d\left(S v, F_{j} v\right) \preceq \frac{\lambda}{2} d\left(S v, F_{j} v\right) \preceq \lambda d\left(S v, F_{j} v\right) .
\end{aligned}
$$

Using Remark 1.3 and Corollary 1.1(3), it follows that $S v=F_{j} v$; therefore, $S v=z=F_{j} v$, that is, $z$ is a coincidence point of $\left(F_{j}, S\right)$ for any even integer $j \in N$.

In case $F_{i} C$ and $F_{j} C$ are closed in $X$, then $z \in F_{i} C \cap C \subseteq S C$ or $z \in F_{j} C \cap C \subseteq T C$. The analogous arguments establish (IV) and (V). If we assume that there exists a subsequence $\left\{S x_{2 n_{k}+1}\right\} \subseteq Q_{0}$ with $T C$ as well as $S C$ closed in $X$, then noting that $\left\{S x_{2 n_{k}+1}\right\}$ is a Cauchy sequence in $S C$, foregoing arguments establish (IV) and (V).

Suppose now that $\left(F_{i}, T\right)$ and $\left(F_{j}, S\right)$ are coincidentally commuting pairs, then

$$
\begin{aligned}
& z=F_{i} w=T w \quad \Rightarrow \quad F_{i} z=F_{i} T w=T F_{i} w=T z \quad \text { and } \\
& z=F_{j} v=S v \quad \Rightarrow \quad F_{j} z=F_{j} S v=S F_{j} v=S z .
\end{aligned}
$$

Then, from (2.2),

$$
d\left(F_{i} z, z\right)=d\left(F_{i} z, F_{j} v\right) \preceq \lambda u,
$$

where

$$
\begin{aligned}
u & \in\left\{d(S v, T z), d\left(T z, F_{i} z\right), d\left(S v, F_{j} v\right), \frac{d\left(T z, F_{j} v\right)+d\left(S v, F_{i} z\right)}{2}\right\} \\
& =\left\{d\left(z, F_{i} z\right), d(z, z), \frac{d\left(F_{i} z, z\right)+d\left(z, F_{i} z\right)}{2}\right\}=\left\{d\left(z, F_{i} z\right), \theta\right\} .
\end{aligned}
$$

Hence, we get the following cases:

$$
\begin{aligned}
& d\left(F_{i} z, z\right) \preceq \lambda d\left(z, F_{i} z\right) \quad \Rightarrow \quad d\left(F_{i} z, z\right)=0, \\
& d\left(F_{i} z, z\right) \preceq \lambda \theta=\theta \quad \Rightarrow \quad d\left(F_{i} z, z\right)=0 .
\end{aligned}
$$

Using Remark 1.3 and Corollary 1.1(3), it follows that $F_{i} z=z$. Thus, $F_{i} z=z=T z$.

Similarly, we can prove $F_{j} z=z=S z$. Therefore $z=F_{i} z=F_{j} z=S z=T z$, that is, $z$ is a common fixed point of $F_{n}, S$ and $T$.

The uniqueness of the common fixed point follows easily from (2.2). 
Example 2.1 Let $E=C^{1}([0,1], R), P=\{\varphi \in E: \varphi(t) \geq 0, t \in[0,1]\}, X=[0,+\infty), C=[0,2]$ and $d: X \times X \rightarrow E$ defined by $d(x, y)=|x-y| \varphi$, where $\varphi \in P$ is a fixed function, $e . g ., \varphi(t)=e^{t}$. Then $(X, d)$ is a complete cone metric space with a non-normal cone having the nonempty interior. Define $F_{i}, F_{j}, S$ and $T: C \rightarrow X$ as

$$
\begin{aligned}
& F_{i} x=x+\frac{4}{5}, \quad i=2 n-1, \quad F_{j} x=x^{2}+\frac{4}{5}, \quad j=2 n, \\
& T x=5 x \quad \text { and } \quad S x=5 x^{2}, \quad x \in C .
\end{aligned}
$$

Since $\partial C=\{0,2\}$. Clearly, for each $x \in C$ and $y \notin C$, there exists a point $z=2 \in \partial C$ such that $d(x, z)+d(z, y)=d(x, y)$. Further, $S C \cap T C=[0,20] \cap[0,10]=[0,10] \supset\{0,2\}=\partial C$, $F_{i} C \cap C=\left[\frac{4}{5}, \frac{14}{5}\right] \cap[0,2]=\left[\frac{4}{5}, 2\right] \subset S C, F_{j} C \cap C=\left[\frac{4}{5}, \frac{24}{5}\right] \cap[0,2]=\left[\frac{4}{5}, 2\right] \subset T C$, and $S C, T C$, $F_{i} C$ and $F_{j} C$ are closed in $X$.

Also,

$$
\begin{aligned}
& T 0=0 \in \partial C \quad \Rightarrow \quad F_{i} 0=\frac{4}{5} \in C, \quad S 0=0 \in \partial C \quad \Rightarrow \quad F_{j} 0=\frac{4}{5} \in C, \\
& T\left(\frac{2}{5}\right)=2 \in \partial C \quad \Rightarrow \quad F_{i}\left(\frac{2}{5}\right)=\frac{6}{5} \in C, \\
& S\left(\sqrt{\frac{2}{5}}\right)=2 \in \partial C \quad \Rightarrow \quad F_{j}\left(\sqrt{\frac{2}{5}}\right)=\frac{6}{5} \in C .
\end{aligned}
$$

Moreover, for each $x, y \in C$,

$$
d\left(F_{i} x, F_{j} y\right)=\left|x-y^{2}\right| \varphi=\frac{1}{5} d(T x, S y)
$$

that is, (2.2) is satisfied with $\lambda=\frac{1}{5}$.

Evidentially, $1=T\left(\frac{1}{5}\right)=F_{i}\left(\frac{1}{5}\right) \neq \frac{1}{5}$ and $1=S\left(\frac{1}{\sqrt{5}}\right)=F_{j}\left(\frac{1}{\sqrt{5}}\right) \neq \frac{1}{\sqrt{5}}$. Notice that two separate coincidence points are not common fixed points as $F_{i} T\left(\frac{1}{5}\right) \neq T F_{i}\left(\frac{1}{5}\right)$ and $S F_{j}\left(\frac{1}{\sqrt{5}}\right) \neq F_{j} S\left(\frac{1}{\sqrt{5}}\right)$, which shows the necessity of coincidentally commuting property in Theorem 2.2.

Next, we furnish an illustrative example in support of our result. In doing so, we are essentially inspired by Imdad and Kumar [21].

Example 2.2 Let $E=C^{1}([0,1], R), P=\{\varphi \in E: \varphi(t) \geq 0, t \in[0,1]\}, X=[1,+\infty), C=[1,3]$ and $d: X \times X \rightarrow E$ defined by $d(x, y)=|x-y| \varphi$, where $\varphi \in P$ is a fixed function, e.g., $\varphi(t)=e^{t}$. Then $(X, d)$ is a complete cone metric space with a non-normal cone having the nonempty interior. Define $F_{i}, F_{j}, S$ and $T: C \rightarrow X$ as

$$
\begin{aligned}
& F_{i} x=\left\{\begin{array}{ll}
\frac{x^{2}-1+n}{n} & \text { if } 1 \leq x \leq 2, \\
\frac{n+1}{n} & \text { if } 2<x \leq 3,
\end{array} \quad i=2 n-1(n \geq 1), \quad T x= \begin{cases}4 x^{4}-3 & \text { if } 1 \leq x \leq 2, \\
13 & \text { if } 2<x \leq 3,\end{cases} \right. \\
& F_{j} x=\left\{\begin{array}{ll}
\frac{x^{3}-1+n}{n} & \text { if } 1 \leq x \leq 2, \\
\frac{n+1}{n} & \text { if } 2<x \leq 3,
\end{array} \quad j=2 n(n \geq 1) \quad \text { and } \quad S x= \begin{cases}4 x^{6}-3 & \text { if } 1 \leq x \leq 2 \\
13 & \text { if } 2<x \leq 3\end{cases} \right.
\end{aligned}
$$


Note that $\partial C=\{1,3\}$. Clearly, for each $x \in C$ and $y \notin C$, there exists a point $z=3 \in \partial C$ such that $d(x, z)+d(z, y)=d(x, y)$. Further, $S C \cap T C=[1,253] \cap[1,61]=[1,61] \supset\{1,3\}=\partial C$, $F_{i} C \cap C=\left[1, \frac{n+3}{n}\right] \cap[1,3] \subset S C$ and $F_{j} C \cap C=\left[1, \frac{n+7}{n}\right] \cap[1,3] \subset T C$.

Also,

$$
\begin{aligned}
& T 1=1 \in \partial C \quad \Rightarrow \quad F_{i} 1=1 \in C, \quad S 1=1 \in \partial C \quad \Rightarrow \quad F_{j} 1=1 \in C, \\
& T\left(\sqrt[4]{\frac{3}{2}}\right)=3 \in \partial C \quad \Rightarrow \quad F_{i}\left(\sqrt[4]{\frac{3}{2}}\right)=\frac{\sqrt{\frac{3}{2}}-1}{n}+1 \in C, \\
& S\left(\sqrt[6]{\frac{3}{2}}\right)=3 \in \partial C \quad \Rightarrow \quad F_{j}\left(\sqrt[6]{\frac{3}{2}}\right)=\frac{\sqrt{\frac{3}{2}}-1}{n}+1 \in C .
\end{aligned}
$$

Moreover, if $x \in[1,2]$ and $y \in[2,3]$, then

$$
d\left(F_{i} x, F_{j} y\right)=\frac{1}{n}\left|x^{2}-2\right| \varphi=\frac{\left|x^{4}-4\right|}{n\left|x^{2}+2\right|} \varphi=\frac{4\left|x^{4}-4\right|}{4 n\left|x^{2}+2\right|} \varphi=\frac{1}{4 n\left(x^{2}+2\right)} d(T x, S y) .
$$

Next, if $x, y \in(2,3]$, then

$$
d\left(F_{i} x, F_{j} y\right)=0=\lambda \cdot d(T x, S y) .
$$

Finally, if $x, y \in[1,2]$, then

$$
d\left(F_{i} x, F_{j} y\right)=\frac{1}{n}\left|x^{2}-y^{3}\right| \varphi=\frac{\left|x^{4}-y^{6}\right|}{n\left|x^{2}+y^{3}\right|} \varphi=\frac{4\left|x^{4}-y^{6}\right|}{4 n\left|x^{2}+y^{3}\right|} \varphi=\frac{1}{4 n\left(x^{2}+y^{3}\right)} d(T x, S y) .
$$

Therefore, condition (2.2) is satisfied if we choose $\lambda=\max \left\{\frac{1}{4 n\left(x^{2}+2\right)}, \frac{1}{4 n\left(x^{2}+y^{3}\right)}\right\} \in(0,1)$. Moreover, 1 is a point of coincidence as $T 1=F_{i} 1$ as well as $S 1=F_{j} 1$, whereas both the pairs $\left(F_{i}, T\right)$ and $\left(F_{j}, S\right)$ are weakly compatible as $T F_{i} 1=1=F_{i} T 1$ and $S F_{j} 1=1=F_{j} S 1$. Also, $S C, T C, F_{i} C$ and $F_{j} C$ are closed in $X$. Thus, all the conditions of Theorem 2.2 are satisfied and 1 is the unique common fixed point of $F_{i}, F_{j}, S$ and $T$. One may note that 1 is also a point of coincidence for both the pairs $\left(F_{i}, T\right)$ and $\left(F_{j}, S\right)$.

Remark 2.1 Setting $F_{i}=F$ and $F_{j}=G$ in Theorem 2.2, we obtain the following result.

Corollary 2.1 Let $(X, d)$ be a complete cone metric space, let $C$ be a nonempty closed subset of $X$ such that for each $x \in C$ and $y \notin C$ there exists a point $z \in \partial C$ such that

$$
d(x, z)+d(z, y)=d(x, y) .
$$

Suppose that $F, G, S, T: C \rightarrow X$ are such that $(F, G)$ is a pair of generalized $(T, S)_{M_{1} \text { - }}$ contractive mappings of $C$ into $X$, and

(I) $\partial C \subseteq S C \cap T C, F C \cap C \subseteq S C, G C \cap C \subseteq T C$,

(II) $T x \in \partial C$ implies that $F x \in C, S x \in \partial C$ implies that $G x \in C$,

(III) SC and TC (or FC and GC) are closed in X.

Then

(IV) $(F, T)$ has a point of coincidence,

(V) $(G, S)$ has a point of coincidence. 
Moreover, if $(F, T)$ and $(G, S)$ are coincidentally commuting pairs, then $F, G, S$ and $T$ have a unique common fixed point.

Remark 2.2 1. Theorem 2.2 in [10] is a special case of Theorem 2.2 with $F_{i}=F_{j}=f, T=$ $S=g$ and $\lambda \in(0, \sqrt{2}-1)$.

2. Setting $F_{i}=F_{j}=f$ and $T=S=I_{X}$ (the identity mapping on $X$ ) in Theorem 2.2, we obtain the following result.

Corollary 2.2 Let $(X, d)$ be a complete cone metric space, and let $C$ be a nonempty closed subset of $X$ such that for each $x \in C$ and $y \notin C$ there exists a point $z \in \partial C$ such that

$$
d(x, z)+d(z, y)=d(x, y) .
$$

Suppose that $f: C \rightarrow X$ satisfies the condition

$$
d(f x, f y) \preceq \lambda u(x, y),
$$

where

$$
u(x, y) \in\left\{d(x, y), d(x, f x), d(y, f y), \frac{d(x, f y)+d(y, f x)}{2}\right\}
$$

for all $x, y \in C, \lambda \in[0,1)$ and $f$ has the additional property that for each $x \in \partial C, f x \in C$. Then $f$ has a unique fixed point.

Remark 2.3 The following definition is a special case of Definition 2.1 when $(X, d)$ is a metric space. But when $(X, d)$ is a cone metric space, which is not a metric space, this is not true. Indeed, there may exist $x, y \in X$ such that the vectors $d\left(T x, F_{i} x\right), d\left(S y, F_{j} y\right)$ and $\frac{d\left(T x, F_{i} x\right)+d\left(S y, F_{j} y\right)}{2}$ are incomparable. For the same reason Theorems 2.2 and 2.3 (given below) are incomparable.

Definition 2.2 Let $(X, d)$ be a complete cone metric space, let $C$ be a nonempty closed subset of $X$, and let $\left\{F_{n}\right\}_{n=1}^{\infty}, S, T: C \rightarrow X$ be non-self mappings. Denote, for $x, y \in C$,

$$
M_{2}^{F_{n}, S, T}=\left\{d(T x, S y), \frac{d\left(T x, F_{i} x\right)+d\left(S y, F_{j} y\right)}{2}, \frac{d\left(T x, F_{j} y\right)+d\left(F_{i} x, S y\right)}{2}\right\},
$$

where $i=2 n-1, j=2 n$ for some $n \in N$. Then $\left(F_{i}, F_{j}\right)$ is called a pair of generalized $(T, S)_{M_{2}-}$ contractive mappings of $C$ into $X$ if for some $\lambda \in[0,1)$ there exists $u(x, y) \in M_{2}^{F_{n}, S, T}$ such that for all $x, y \in C$ with $x \neq y$,

$$
d\left(F_{i} x, F_{j} y\right) \preceq \lambda u(x, y) .
$$

Our next result is the following.

Theorem 2.3 Let $(X, d)$ be a complete cone metric space, let $C$ be a nonempty closed subset of $X$ such that for each $x \in C$ and $y \notin C$ there exists a point $z \in \partial C$ such that

$$
d(x, z)+d(z, y)=d(x, y)
$$


Suppose that $F_{n}, S, T: C \rightarrow X$ are such that $\left(F_{i}, F_{j}\right)$ is a pair of generalized $(T, S)_{M_{2}}$ contractive mappings of $C$ into $X$ for all $i=2 n-1, j=2 n(n \in N)$, and

(I) $\partial C \subseteq S C \cap T C, F_{i} C \cap C \subseteq S C, F_{j} C \cap C \subseteq T C$,

(II) $T x \in \partial C$ implies that $F_{i} x \in C, S x \in \partial C$ implies that $F_{j} x \in C$,

(III) $S C$ and $T C$ (or $F_{i} C$ and $F_{j} C$ ) are closed in $X$.

Then

(IV) $\left(F_{i}, T\right)$ has a point of coincidence,

(V) $\left(F_{j}, S\right)$ has a point of coincidence.

Moreover, if $\left(F_{i}, T\right)$ and $\left(F_{j}, S\right)$ are coincidentally commuting pairs, then $F_{n}, S$ and $T$ have a unique common fixed point.

The proof of this theorem is very similar to the proof of Theorem 2.2 and it is omitted.

Remark 2.4 Setting $F_{i}=F$ and $F_{j}=G$ in Theorem 2.3, we obtain the following result.

Corollary 2.3 Let $(X, d)$ be a complete cone metric space, let $C$ be a nonempty closed subset of $X$ such that for each $x \in C$ and $y \notin C$ there exists a point $z \in \partial C$ such that

$$
d(x, z)+d(z, y)=d(x, y) .
$$

Suppose that $F, G, S, T: C \rightarrow X$ are such that $(F, G)$ is a pair of generalized $(T, S)_{M_{2}-}$ contractive mappings of $C$ into $X$, and

(I) $\partial C \subseteq S C \cap T C, F C \cap C \subseteq S C, G C \cap C \subseteq T C$,

(II) $T x \in \partial C$ implies that $F x \in C, S x \in \partial C$ implies that $G x \in C$,

(III) SC and TC (or FC and GC) are closed in X.

Then

(IV) $(F, T)$ has a point of coincidence,

(V) $(G, S)$ has a point of coincidence.

Moreover, if $(F, T)$ and $(G, S)$ are coincidentally commuting pairs, then $F, G, S$ and $T$ have a unique common fixed point.

We now list some corollaries of Theorems 2.2 and 2.3.

Corollary 2.4 Let $(X, d)$ be a complete cone metric space, let $C$ be a nonempty closed subset of $X$ such that for each $x \in C$ and $y \notin C$ there exists a point $z \in \partial C$ such that

$$
d(x, z)+d(z, y)=d(x, y) .
$$

Let $F_{n}, S, T: C \rightarrow X$ be such that

$$
d\left(F_{i} x, F_{j} y\right) \preceq \lambda d(T x, S y)
$$

for some $\lambda \in[0,1)$ and for all $i=2 n-1, j=2 n(n \in N), x, y \in C$ with $x \neq y$.

Suppose, further, that $F_{n}, S, T$ and $C$ satisfy the following conditions:

(I) $\partial C \subseteq S C \cap T C, F_{i} C \cap C \subseteq S C, F_{j} C \cap C \subseteq T C$,

(II) $T x \in \partial C$ implies that $F_{i} x \in C, S x \in \partial C$ implies that $F_{j} x \in C$,

(III) $S C$ and $T C$ (or $F_{i} C$ and $F_{j} C$ ) are closed in $X$. 
Then

(IV) $\left(F_{i}, T\right)$ has a point of coincidence,

(V) $\left(F_{j}, S\right)$ has a point of coincidence.

Moreover, if $\left(F_{i}, T\right)$ and $\left(F_{j}, S\right)$ are coincidentally commuting pairs, then $\left\{F_{n}\right\}_{n=1}^{\infty}$, S and $T$ have a unique common fixed point.

Corollary 2.5 Let $(X, d)$ be a complete cone metric space, let $C$ be a nonempty closed subset of $X$ such that for each $x \in C$ and $y \notin C$ there exists a point $z \in \partial C$ such that

$$
d(x, z)+d(z, y)=d(x, y)
$$

Let $F_{n}, S, T: C \rightarrow X$ be such that

$$
d\left(F_{i} x, F_{j} y\right) \preceq \lambda\left(d\left(T x, F_{i} x\right)+d\left(S y, F_{j} y\right)\right)
$$

for some $\lambda \in[0,1 / 2)$ and for all $i=2 n-1, j=2 n(n \in N), x, y \in C$ with $x \neq y$.

Suppose, further, that $F_{n}, S, T$ and $C$ satisfy the following conditions:

(I) $\partial C \subseteq S C \cap T C, F_{i} C \cap C \subseteq S C, F_{j} C \cap C \subseteq T C$,

(II) $T x \in \partial C$ implies that $F_{i} x \in C, S x \in \partial C$ implies that $F_{j} x \in C$,

(III) $S C$ and $T C$ (or $F_{i} C$ and $F_{j} C$ ) are closed in $X$.

Then

(IV) $\left(F_{i}, T\right)$ has a point of coincidence,

(V) $\left(F_{j}, S\right)$ has a point of coincidence.

Moreover, if $\left(F_{i}, T\right)$ and $\left(F_{j}, S\right)$ are coincidentally commuting pairs, then $\left\{F_{n}\right\}_{n=1}^{\infty}, S$ and $T$ have a unique common fixed point.

Corollary 2.6 Let $(X, d)$ be a complete cone metric space, let $C$ be a nonempty closed subset of $X$ such that for each $x \in C$ and $y \notin C$ there exists a point $z \in \partial C$ such that

$$
d(x, z)+d(z, y)=d(x, y)
$$

Let $F_{n}, S, T: C \rightarrow X$ be such that

$$
d\left(F_{i} x, F_{j} y\right) \preceq \lambda\left(d\left(T x, F_{j} y\right)+d\left(F_{i} x, S y\right)\right)
$$

for some $\lambda \in[0,1 / 2)$ and for all $i=2 n-1, j=2 n(n \in N), x, y \in C$ with $x \neq y$.

Suppose, further, that $F_{n}, S, T$ and $C$ satisfy the following conditions:

(I) $\partial C \subseteq S C \cap T C, F_{i} C \cap C \subseteq S C, F_{j} C \cap C \subseteq T C$,

(II) $T x \in \partial C$ implies that $F_{i} x \in C, S x \in \partial C$ implies that $F_{j} x \in C$,

(III) $S C$ and $T C$ (or $F_{i} C$ and $F_{j} C$ ) are closed in $X$.

Then

(IV) $\left(F_{i}, T\right)$ has a point of coincidence,

(V) $\left(F_{j}, S\right)$ has a point of coincidence.

Moreover, if $\left(F_{i}, T\right)$ and $\left(F_{j}, S\right)$ are coincidentally commuting pairs, then $\left\{F_{n}\right\}_{n=1}^{\infty}, S$ and $T$ have a unique common fixed point. 
Remark 2.5 Setting $F_{i}=F_{j}=f$ and $T=S=g$ in Corollaries 2.4-2.6, we obtain the following result.

Corollary 2.7 Let $(X, d)$ be a complete cone metric space, let $C$ be a nonempty closed subset of $X$ such that for each $x \in C$ and $y \notin C$ there exists a point $z \in \partial C$ such that

$$
d(x, z)+d(z, y)=d(x, y) .
$$

Let $f, g: C \rightarrow X$ be such that

$$
d(f x, f y) \preceq \lambda d(g x, g y)
$$

for some $\lambda \in[0,1)$ and for all $x, y \in C$. Suppose, further, that $f, g$ and $C$ satisfy the following conditions:

(I) $\partial C \subseteq g C, f C \cap C \subseteq g C$,

(II) $g x \in \partial C$ implies that $f x \in C$,

(III) $g C$ is closed in $X$.

Then there exists a coincidence point $z$ of $f, g$ in C. Moreover, if $(f, g)$ are coincidentally commuting, then $z$ is the unique common fixed point off and $g$.

Corollary 2.8 Let $(X, d)$ be a complete cone metric space, let $C$ be a nonempty closed subset of $X$ such that for each $x \in C$ and $y \notin C$ there exists a point $z \in \partial C$ such that

$$
d(x, z)+d(z, y)=d(x, y)
$$

Let $f, g: C \rightarrow X$ be such that

$$
d(f x, f y) \preceq \lambda(d(f x, g x)+d(f y, g y))
$$

for some $\lambda \in[0,1 / 2)$ and for all $x, y \in C$. Suppose, further, that $f, g$ and $C$ satisfy the following conditions:

(I) $\partial C \subseteq g C, f C \cap C \subseteq g C$,

(II) $g x \in \partial C$ implies that $f x \in C$,

(III) $g C$ is closed in $X$.

Then there exists a coincidence point $z$ of $f, g$ in C. Moreover, if $(f, g)$ are coincidentally commuting, then $z$ is the unique common fixed point off and $g$.

Corollary 2.9 Let $(X, d)$ be a complete cone metric space, let $C$ be a nonempty closed subset of $X$ such that for each $x \in C$ and $y \notin C$ there exists a point $z \in \partial C$ such that

$$
d(x, z)+d(z, y)=d(x, y) .
$$

Let $f, g: C \rightarrow X$ be such that

$$
d(f x, f y) \preceq \lambda(d(f x, g y)+d(f y, g x))
$$

for some $\lambda \in[0,1 / 2)$ and for all $x, y \in C$. Suppose, further, that $f, g$ and $C$ satisfy the following conditions: 
(I) $\partial C \subseteq g C, f C \cap C \subseteq g C$,

(II) $g x \in \partial C$ implies that $f x \in C$,

(III) $g C$ is closed in $X$.

Then there exists a coincidence point $z$ of $f, g$ in C. Moreover, if $(f, g)$ are coincidentally commuting, then $z$ is the unique common fixed point off and $g$.

Remark 2.6 Corollaries 2.7-2.9 are the corresponding theorems of Abbas and Jungck from [2] in the case that $f, g$ are non-self mappings.

\section{Competing interests}

The authors declare that they have no competing interests.

\section{Authors' contributions}

All authors contributed equally and significantly in writing this paper. All authors read and approved the final manuscript.

\section{Author details}

'Department of Mathematics, Nanchang University, Nanchang, Jiangxi 330031, P.R. China. ${ }^{2}$ Department of Computer Science, Nanchang University, Nanchang, Jiangxi 330031, P.R. China. ${ }^{3}$ Faculty of Mechanical Engineering, University of Kragujevac, Dositejeva 19, Kraljevo, 36 000, Serbia.

\section{Acknowledgements}

The authors would like to express their sincere appreciation to the referees for their very helpful suggestions and kind comments. Project is supported by the National Natural Science Foundation of China (11071108) and supported partly by the Provincial Natural Science Foundation of Jiangxi, China (20114BAB201003) and the Science and Technology

Project of Educational Commission of Jiangxi Province, China (GJJ11346).

\section{Received: 17 December 2012 Accepted: 15 April 2013 Published: 4 June 2013}

\section{References}

1. Huang, LG, Zhang, X: Cone metric spaces and fixed point theorems of contractive mappings. J. Math. Anal. Appl. 332, 1468-1476 (2007)

2. Abbas, M, Jungck, G: Common fixed point results for noncommuting mappings without continuity in cone metric spaces. J. Math. Anal. Appl. 341(1), 416-420 (2008)

3. Abbas, M, Rhoades, BE: Fixed and periodic point results in cone metric spaces. Appl. Math. Lett. 22, $511-515$ (2009)

4. Berinde, $\mathrm{V}$ : Common fixed points of noncommuting discontinuous weakly contractive mappings in cone metric spaces. Taiwan. J. Math. 14(5), 1763-1776 (2010)

5. Huang, XJ, Zhu, CX, Wen, X: Common fixed point theorem for four non-self mappings in cone metric spaces. Fixed Point Theory Appl. 2010, Article ID 983802 (2010). doi:10.1155/2010/983802

6. Huang, XJ, Zhu, CX, Wen, X: Common fixed point theorem for a family of non-self mappings in cone metric spaces. Hacet. J. Math. Stat. 41(6), 853-865 (2012)

7. Huang, XJ, Zhu, CX, Wen, X: Fixed point theorems for expanding mappings in cone metric spaces. Math. Rep. 14(2), 141-148 (2012)

8. Ilić, D, Rakocević, V: Common fixed points for maps on cone metric space. J. Math. Anal. Appl. 341(2), 876-882 (2008)

9. Janković, S, Kadelburg, Z, Radenović, S: On cone metric spaces: a survey. Nonlinear Anal. 74, 2591-2601 (2011)

10. Janković, S, Kadelburg, Z, Radenović, S, Rhoades, BE: Assad-Kirk-type fixed point theorems for a pair of nonself mappings on cone metric spaces. Fixed Point Theory Appl. 2009, Article ID 761086 (2009). doi:10.1155/2009/761086

11. Jungck, G, Radenovic, S, Radojević, S, Rakočević, V: Common fixed point theorems for weakly compatible pairs on cone metric spaces. Fixed Point Theory Appl. 2009, Article ID 643840 (2009). doi:10.1155/2009/643840

12. Kadelburg, Z, Radenović, S, Rakočević, V: A note on the equivalence of some metric and cone metric fixed point results. Appl. Math. Lett. 24, 370-374 (2011)

13. Radenović, S: A pair of non-self mappings in cone metric spaces. Kragujev. J. Math. 36(2), 189-198 (2012)

14. Radenović, S, Rhoades, BE: Fixed point theorem for two non-self mappings in cone metric spaces. Comput. Math. Appl. 57, 1701-1707 (2009)

15. Rezapour, S, Hamlbarani, R: Some notes on the paper 'Cone metric spaces and fixed point theorems of contractive mappings.' J. Math. Anal. Appl. 345, 719-724 (2008)

16. Vetro, P: Common fixed points in cone metric spaces. Rend. Circ. Mat. Palermo LVI, 464-468 (2007)

17. Wardowski, D: Endpoints and fixed points of set-valued contractions in cone metric space. Nonlinear Anal. 71 , 512-516 (2009)

18. Assad, NA, Kirk, WA: Fixed point theorems for set valued mappings of contractive type. Pac. J. Math. 43(3), 553-562 (1972)

19. Wong, YC, Ng, KF: Partially Ordered Topological Vector Spaces. Clarendon, Oxford (1973)

20. Hadzic, O, Gajic, L: Coincidence points for set-valued mappings in convex metric spaces. Univ. Novom. Sadu. Zb. Rad. Prirod. Mat. Fak. Ser. Mat. 16(1), 13-25 (1986)

21. Imdad, M, Kumar, S: Rhoades-type fixed point theorems for a pair of non-self mappings. Comput. Math. Appl. 46 , 919-927 (2003) 
doi:10.1186/1687-1812-2013-144

Cite this article as: Huang et al.: Some common fixed point theorems for a family of non-self mappings in cone metric spaces. Fixed Point Theory and Applications 2013 2013:144.

Submit your manuscript to a SpringerOpen ${ }^{\circ}$ journal and benefit from:

- Convenient online submission

- Rigorous peer review

- Immediate publication on acceptance

- Open access: articles freely available online

- High visibility within the field

- Retaining the copyright to your article

Submit your next manuscript at $\gg$ springeropen.com 